\title{
Restorative justice conferencing: Not a panacea for the over-representation of Australia's Indigenous youth in the criminal justice system
}

\author{
Simon Little, Anna Stewart \& Nicole Ryan \\ School of Criminology and Criminal Justice \\ Griffith Criminology Institute \\ Griffith University
}

Australia

Submission accepted by

International Journal of Offender Therapy and Comparative Criminology

February 17, 2018

Correspondence addressing this article should be directed to:

Simon Little, School of Criminology and Criminal Justice, Griffith University

Social Sciences (M10) Building, 176 Messines Ridge Road, Mount Gravatt QLD 4122, Australia

Phone: + 617 37356809. Email: s.little@griffith.edu.au

Simon Little is a lecturer in the School of Criminology and Criminal Justice, Griffith University, Australia. He earned his $\mathrm{PhD}$ (2015) in criminology and criminal justice from Griffith University for his thesis examining the effectiveness of diversionary strategies for reducing youth recidivism, compared with traditional court processing. His primary areas of research include youth justice, youth offending, restorative justice, and program evaluation.

Anna Stewart is a Professor in the School of Criminology and Criminal Justice, Griffith University, Australia. Her research history includes innovative work in linking and analysing administrative data and considerable success at translating findings into policy and practice. Anna has been a Chief Investigator on projects that have attracted over $\$ 4.5$ million in funding and published over 80 peer-reviewed publications, government reports and non peerreviewed publications.

Nicole Ryan is a doctoral student in the Department of Criminal Justice and Criminology at Griffith University. She was awarded a First Class Honours in Criminology and Criminal Justice (2014), completed her Bachelor in Criminology and Criminal Justice (2013) at Griffith University. Her primary areas of research include corrections, prisoner reintegration, and race conflict. Additional interests include public perceptions to sentencing, rehabilitation and restoration, youth justice, and restorative justice. 
The over-representation of Australia's First Nations People in the criminal justice system remains a significant public policy issue and has received significant attention by criminological scholars for the past 25 years. ${ }^{i}$ The impetus of this scholarly attention stems from the Royal Commission into Aboriginal Deaths in Custody (RCIADIC), which found the central problem was high rates of Indigenous over-representation at all stages of the criminal justice system (Johnston, 1991). Despite this significant focus over the past quarter century, this rate of over-representation for Indigenous people not only remains, but has increased (Weatherburn, 2014). Within Queensland, Indigenous people represent $4.2 \%$ of the total population (Australian Bureau of Statistics, 2013), yet they have an age-standardised imprisonment rate 10 times that of non-Indigenous people (Productivity Commission, 2016). This trend is more pronounced within the youth justice system, where Indigenous young people aged 10-16 years are 26 times more likely to be in youth detention facilities than nonIndigenous young people (Australian Institute of Health and Welfare, 2016).

In 2000, in recognition of this critical policy issue, the Queensland government signed the Queensland Aboriginal and Torres Strait Islander Justice Agreement (ATSIJA), proposing to reduce the imprisonment rate of Australia's Indigenous people by $50 \%$ before 2010 , the $20^{\text {th }}$ anniversary of the RCIADIC. Five years later, an independent review of the progress of the Agreement noted that a contributing factor to over-representation was that diversionary programs were not adequately used to channel young Indigenous offenders from formal court processing, resulting in further entrenchment within the youth justice system (Cunneen, Collings, \& Ralph, 2005). To achieve a reduction in the rate of overrepresentation, an increase in the rates of referral to diversionary programs such as restorative justice (RJ) conferencing was proposed (Cunneen et al., 2005). ${ }^{\mathrm{ii}}$

The strategy to decrease Indigenous over-representation within the youth justice system through an increase in diversion presupposes that conferencing is effective at reducing 
reoffending. There is a burgeoning literature demonstrating that conferencing and other RJ interventions have better recidivism outcomes when compared to traditional court processing (Bergseth \& Bouffard, 2013; Sherman, Strang, Mayo-Wilson, Woods, \& Ariel, 2015; Wong, Bouchard, Gravel, Bouchard, \& Morselli, 2016). However, there is a scarcity of research examining how effective conferencing is at reducing recidivism by race (Baffour, 2006). The current study aims to fill this gap in the literature by examining the efficacy of conferencing for reducing recidivism by Indigenous young people compared to non-Indigenous young people.

\section{Indigenous over-representation}

The over-representation of Indigenous peoples in the criminal justice system is not a new phenomenon, and appears to be a finding consistent across post-colonial societies. Comparative countries such as Canada and New Zealand similarly grapple with the problem of Indigenous over-representation, albeit to a level much lower than we find in Australia (Caverley, Cotter, \& Halla, 2010; Department of Corrections, 2007). This high rate of imprisonment has implications more far-reaching than for the individual incarcerated. First, there are suggestions that the high rate of arrest, prosecution and imprisonment among Indigenous populations (and across generations) may have nullified the deterrent effects of contact with the criminal justice system (Weatherburn, 2014). Statistics indicate that one in five Indigenous children have had a parent incarcerated during their formative years (Quilty, Levy, Howard, Barratt, \& Butler, 2004), resulting in conditions associated with increased involvement of offending for young people, such as single parent families, reductions in income, and reductions in parental supervision (Weatherburn, 2014; Weatherburn \& Lind, 2000). This also results in conditions conducive to an increase in imprisonment rates for the next generation. 
It is not just in rates of contact with the criminal justice system where there is disparity between Indigenous and non-Indigenous people. Indigenous people experience complex disadvantage that results in social exclusion (Hunter, 2009), and the Australian Government has prioritised initiatives to 'close the gap' between Indigenous and nonIndigenous peoples on a range of key health (life expectancy and mortality rates), education (rates of literacy and school completion) and employment indicators. For example, Indigenous communities are characterised by concentrated disadvantage that includes poverty, substance abuse, violence, overcrowding, teenage pregnancies, and high crime rates; as well as low levels of nutrition, parental supervision and academic attainment (Weatherburn \& Lind, 2000).

The role of social and economic disadvantage in the contact that Indigenous young people have with the criminal justice system cannot be understated. According to the RCIADIC, "the single significant contributing factor to incarceration is the disadvantaged and unequal position of Aboriginal people in Australia, in every way, whether socially, economically or culturally" (Johnston, 1991, p. 15). Over a decade later, Weatherburn, Snowball and Hunter (2008) found that economic and social disadvantage (measured by unemployment, financial stress, welfare dependency and failure to complete secondary school) were significant predictors of Indigenous arrest and imprisonment, after controlling for factors that might be expected to influence contact with the criminal justice system (e.g., age, gender, residential location, school performance, and family structure).

\section{Diversion}

In recognition of the different developmental stages and needs of children, youth justice systems have developed a range of alternative policy options and programs to respond to youth offending, including diversion. Diversion may broadly be defined as "what happens 
to those offenders for whom there is a conscious decision not to use the formal process of prosecution and trial in cases where there is a fair expectation that it would otherwise have taken place" (Farrington \& Bennett, 1981, p. 2). Such strategies focus on minimising the level of penetration that young offenders have within the formal processes of the youth justice system.

In Australia, diversion commonly refers to pre-court diversion, and is used to redirect offenders away from the more formal processes of the criminal justice system, such as the courts. This approach differs to the primary diversionary approach within the United States and other countries, where diversion tends to redirect young people to short-term communitybased treatment programs emphasising interventions such as counselling and therapy (for example, see Lipsey, 2009; Wilson \& Hoge, 2013). One of the main pre-court diversionary strategies used in response to offending by young people in Australian jurisdictions is a RJ intervention: conferencing.

\section{Eligibility for conferencing of young offenders in Queensland}

Conferencing is a diversionary option that may be used in response to offending by young people between (and including) the ages of 10 to 16 years. To be eligible for a conference young people must admit to the offence and consent to being conferenced. In basing their decision to refer a young offender to a conference, a police officer may consider the seriousness of the offence, and their criminal history. However, persistent and/or, serious young offenders remain eligible for referral. While a young offender may also be referred by a court magistrate if the young person admits guilt and the magistrate believes the offence should be dealt with via a conference process, the current study only focuses on young offenders referred by police to a conference. 
The youth justice conference process brings together the offender, their victims and supporters in facilitated mediation. This is aimed at encouraging young people to take responsibility for their actions, and addressing the offence and its impact while repairing the harm caused by the crime (Hayes \& Daly, 2004). At the conclusion of the conference, an outcome plan is formulated, where agreement is made between the participants as to how the young person can 'make amends' for the offence (Hayes \& Daly, 2003). This most often involves the young person offering a verbal or written apology, but may also include community service or restitution to the victim (Hayes \& Daly, 2003). Where the offender is an Indigenous young person, a respected member of the Indigenous or elder may be asked to attend the conference.

\section{Theoretical foundations of conferencing}

Conferences are an alternative to the traditional or conventional response of prosecution provided by the youth court system in Australian jurisdictions. A conference involves a scheduled and facilitated dialogue between an offender, the victim, their respective family, and supporters and other stakeholders in the community in order to decide how to best repair the harm that a crime has caused (Sherman et al., 2015). In addition to this, repairing the harm caused by the crime, a key focus of these interventions is encouraging offender accountability.

The basis for conferencing is entrenched within principles of RJ. While there is considerable debate concerning how RJ is best defined and conceptualised, it is often viewed as an alternative to traditional justice practices, and brings together parties impacted by a crime to discuss the impact of an offence, and how to respond to the offence in a way that repairs its harm in facilitated dialogue (Hayes \& Daly, 2004). 
An additional theoretical basis for RJ interventions such as conferencing is reintegrative shaming (Braithwaite, 1989). According to Braithwaite, social processes that elicit remorse in offenders are more effective at deterring future criminal behaviour than traditional justice processing. A key part of this process is shaming. Reintegrative shaming is characterised by a ceremony where community members and those close to them denounce the criminal act rather than the offender. Following the shaming ceremony, efforts are made to "reintegrate the offender back into the community of law-abiding or respectable citizens through words or gestures of forgiveness or ceremonies to decertify the offender as deviant" (Braithwaite, 1989, pp. 100-101). Braithwaite (2002) contends that reintegrative shaming maintains social bonds that exert informal social control over an offender's behaviour, and is likely to prevent crime if the key aims of RJ (accountability, restoration, reparation and meeting victim needs) are achieved.

Reintegrative shaming presumes elements of procedural justice (Tyler, 1990) which emphasises respect, the neutrality of decision-makers, and just treatment. According to this theory, offenders are less likely to reoffend when they perceive their treatment from authorities to be just, resulting in increased beliefs about the legitimacy of the law, and increases compliance with the law (Tyler, Sherman, Strang, Barnes, \& Woods, 2007).

Although the concept of RJ has a lineage that is claimed to have derived from Indigenous justice traditions (Strang, 2001), debate has centred on the appropriateness and effectiveness of conferencing in Indigenous communities. Notwithstanding contentions regarding its purported origins from Indigenous justice principles (Daly, 2002), criticisms centre on two main areas. First, Indigenous people have had these practices imposed upon them without consultation, involvement of local communities and organisations, and without attention paid to cultural differences; second, there are concerns about the discretionary powers of police in decisions to refer young people to these programs (Blagg, 1997; 
Cunneen, 1997). Despite these criticisms and debates around the roots of these practices, conferencing may be considered a more culturally appropriate justice response compared to traditional justice processing for Indigenous young people due to the focus on improved communication in an informal setting between legal authorities, offenders, victims and community members, and an emphasis on procedural justice (Marchetti \& Daly, 2007).

\section{Conferencing and reoffending}

In contrast to conventional justice and its focus on punishment and deterrence, the primary goal of RJ is reparation from the harm caused by crime, for offenders, victims and the wider community (Morris, 2002). Understandably then, the literature is dominated by studies focusing on perceptions of fairness and satisfaction of the process (Gal \& Moyal, 2011; Kim \& Gerber, 2012; Tyler et al., 2007; Van Camp \& Wemmers, 2013) and intermediate outcomes such as achieving offender accountability and repairing harm (Calhoun \& Pelech, 2010). Regardless of the primary aims of RJ, the litmus test for policymakers remains its ability to reduce or prevent reoffending.

The majority of studies examining the impact of $\mathrm{RJ}$ approaches report reductions in reoffending outcomes post-contact, especially when compared to court or traditional nonrestorative approaches (Bergseth \& Bouffard, 2007, 2013; Bouffard, Cooper, \& Bergseth, 2016; de Beus \& Rodriguez, 2007; Hayes \& Daly, 2004; Latimer, Dowden, \& Muise, 2005; Little, Allard, Chrzanowski, \& Stewart, 2011; Sherman et al., 2015; Sherman, Strang, \& Woods, 2000). A recent meta-analysis focusing on randomised controlled trials of conferences found them to be a cost-effective means to reduce the frequency of recidivism (Sherman et al., 2015), although the criteria for the research were predominantly focused on adult offenders. A second meta-analysis that included studies that were predominantly 
focused on youth offenders (Latimer et al., 2005) also found that on average, such programs yielded reductions in recidivism.

While there is a burgeoning literature suggesting that conferencing is effective at reducing recidivism, there is considerable variation in the effects reported. There are two explanations for the mixed findings. The first explanation is the heterogeneity of research designs and methodological rigour between studies, such as having an appropriate comparison group and controlling for offence and offender characteristics (Weatherburn \& Macadam, 2013). Randomised controlled trials may be considered the 'gold standard' of evaluation evidence for their ability to control for selection bias and demonstrate that a change in a treatment effected a change in an outcome (Nagin \& Weisburd, 2013). However, it would be unethical to randomly assign young offenders into groups based on race. Further, it is also not possible to do with observational data. In such instances, we seek alternatives to account for pre-existing differences between groups, such as statistical control offered by propensity score matching (PSM) (Rosenbaum \& Rubin, 1983). Despite concern about the use of PSM for creating comparison groups based on a condition where the subject has no chance to be in either conditions, such as gender or race (Shadish, 2013), PSM has been used frequently as a means to delineate groups based on race (Higgins, Jennings, Jordan, \& Gabbidon, 2011; Higgins, Ricketts, Griffith, \& Jirard, 2013; Ridgeway, 2006; Stringer \& Holland, 2016). Indeed, PSM has been advocated for its use in creating a reference group for ethnicity to deal with potential confounders in ways that conventional regression techniques do not allow (Ye, Bond, Schmidt, Mulia, \& Tam, 2012).

The second explanation for mixed findings about reoffending outcomes might be the possibility of the differential effectiveness of conferencing. This was noted by Rodriguez (2007, p. 363) who stated that research should move "beyond the question of whether RJ programs can be successful at reducing crime and addressing the circumstances under which 
programs can be most effective". In this vein, studies have examined whether there is a differential effectiveness of conferencing across offence categories, offender characteristics, and variations in programming (Bergseth \& Bouffard, 2013; Bouffard et al., 2016; de Beus \& Rodriguez, 2007; Sherman et al., 2000). It is important to understand the differential nature of programs to understand the potential contribution of such programs to meeting ATSIJA targets. Thus, we aim to examine if there is a differential impact of conferencing by race, or more specifically, the examine whether conferencing is effective at preventing reoffending for Indigenous youth compared to non-Indigenous youth. We justify the use of PSM in this study as a means to balance the covariates between the two groups and allow a more rigorous examination of a potential differential impact of conferencing by race.

\section{Current Study}

In the current study, we aim to examine the differential impact of conferencing on young offenders. ${ }^{\text {iii }}$ Specifically, we aim to explore whether this diversionary strategy has a differential impact for Indigenous compared to non-Indigenous young people. ${ }^{\text {iv }}$ Despite a growing body of literature on conferencing, there is a lack of research examining whether there is a differential impact on recidivism by race. This is important to help understand what impact, if any, conferencing may have on young offenders, and whether this strategy is likely to adequately address the issue of Indigenous over-representation within the criminal justice system. Specifically, the study addressed three research questions:

1. Are Indigenous young people less likely than non-Indigenous young people to reoffend within two years of attending their first police-referred conference?

2. Of those young people who did reoffend, is there an association between Indigenous status and an increase in offending severity after attending their first police-referred conference? 
3. Of those young people who did reoffend after their first conference, is there a difference in the time-to-reoffence between Indigenous and non-Indigenous young people?

These outcomes were selected to provide a more detailed examination of the impact of conferencing on recidivism beyond a simplistic measure of whether an offender had further contact with the criminal justice system. By examining these additional dimensions of seriousness and the time to reoffending, we can gain a greater understanding of whether there is a differential impact of conferencing by race.

\section{Method}

\section{Data Source}

This study uses data from the Queensland Longitudinal Database (QLD90) that contains the offending profiles of all individuals born in 1990 who were guilty of an offence in Queensland when aged between 10 and 19.5 years old $(n=7,900)$. In Queensland, the minimum age of criminal responsibility is 10 years of age, and a young person is considered a youth until their seventeenth birthday. During this period, the youth justice system officially responds to offending behaviour by young people through diversion (to a formal police caution or referral to conference) or formal processing through the youth court system. Upon turning 17 years of age when the legislation considers a young person to be an adult, the criminal justice system responds through formal processing by the adult court system. By including formal contact with the criminal justice system to 19.5 years of age, the data contains a follow-up period that extends into young adulthood.

The database was created by linking the offence-based datasets related to each criminal justice outcome (i.e., formal police caution, police-referred conference, youth court appearance and adult court appearance), providing an offending profile representing official contact with the criminal justice system. While the use of official records are useful to 
estimate criminal involvement, they are not a measurement of all crime committed as it cannot control for victim decisions to report a crime, nor control for discretionary decisions by criminal justice agents for an offence to result in a formal event (Piquero, Schubert, \& Brame, 2014). The database has been used extensively for research, with the data linkage and cleaning processes described elsewhere (Little et al., 2011).

The data contains the offending profiles of 7,900 individuals who had formal contact with the youth justice system. Of these individuals, police referred 806 young offenders to a conference. The demographic profiles of the young offenders who had any contact with the youth justice system, and specifically those who referred by police to a conference at any point as a youth, is presented in Table 1.

\section{[ Insert Table 1 about here]}

While there appears to be no noticeable difference in rates of referral to conferencing by gender, there appears to be differences by race. Despite claims that Indigenous young people are not afforded the same opportunity for diversion as their non-Indigenous counterparts (Cunneen et al., 2005; Cunneen, Goldson, \& Russell, 2016), these data suggests otherwise. While Indigenous young people constitute $18 \%$ of the entire cohort who had formal contact with the youth justice system, they comprise $29 \%$ of all young people police referred to a conference. Thus, police diverted Indigenous young people to a conference at a higher rate, relative to their proportion of the cohort. We now direct our interest to examine whether there is a differential impact on recidivism post-conference by race.

\section{Measures}

Dependent variables 
Reoffend within two years. We operationalise reoffending as any new offence that was detected by the police and resulted in a formal police caution, a police-referred conference, or a guilty verdict at a finalised youth or adult court appearance after attending their first policereferred conference. In this way, our measure of recidivism specifically reflects a young person having formal system recontact resulting from a subsequent offence. We focus on reoffending within a specific time frame of two years of an offender's first police-referred conference to allow for a consistent and equal follow-up period, regardless of the age at which someone was conferenced $(1=$ yes and $0=$ no). As our data extends into young adulthood, we are able to follow-up those offenders whose conference was held before becoming an adult at 17 years of age.

Increase in offending severity. As a second dimension of recidivism, we also examine whether, for those who reoffend, that there is an increase in the seriousness of their offending post-conference. We assessed this by comparing the offence that resulted in referral to conference with any subsequent reoffending, by using the National Offence Index (NOI), which is a tool that provides an ordinal ranking of offence categories according to the perceived seriousness (Australian Bureau of Statistics, 2009).

Time to reoffence. A third dimension of recidivism was the time (in days) to reoffending. We use survival or hazards models to examine the time to recontact due to the nature of the censored data and varied follow-up times (Spruance, Reid, Grace, \& Samore, 2004). We employ Cox Proportional-Hazards regression survival analysis to assess whether there were differences in hazard or survival rates by race. The hazard of recidivism will reflect the chances of reoffending (for those who have not yet reoffended) for Indigenous young people compared to non-Indigenous young people.

Independent Variables 
Indigenous status. A young person is recorded as Indigenous if they had ever self-identified ( $1=$ Indigenous, $0=$ Non-Indigenous). This aligns with best practice for the recording of Indigenous status (Australian Institute of Health and Welfare, 2012).

\section{Covariates}

Age at conference. The age of the participant at their first conference (continuous measure).

Sex. The sex of the young offender $(1=$ male, $0=$ female $)$.

Remote location. The vast size of Queensland has important implications for the access to services due to the remoteness of communities. The remoteness of an offender's usual residential location was based on the Accessibility/Remoteness Index of Australia (ARIA) (Australian Bureau of Statistics, 2006). The ARIA index measures how remote a community is, based on the distance of road travel between a location and the nearest town centre. The population size of the town is used as a proxy for the availability of range and services, while the road distance is used as a proxy for the remoteness from those services. The location of the offender's usual residential address was binary coded $(1=$ remote, $0=$ not remote $)$.

Lowest Socioeconomic Area. A proxy measure of socioeconomic status for an offender's usual residential location was provided by the Index of Relative Socio-Economic Disadvantage (IRSD) (Australian Bureau of Statistics, 2008). The index represents a measure of collective socioeconomic status for residents within an area, and does not reflect specific individual measures of poverty. The index is based on a number of factors, such as the proportion of one parent families, the proportion of unemployed and the proportion of people with low household incomes (lowest quintile of the IRSD $=1$, all others $=0$ ).

Serious violent offence. Whether the index offence was from a range of offences deemed serious and with a violent component. This included homicide and related offences, abduction, robbery, serious assault resulting in injury, and aggravated sexual assault $(1=$ yes, $0=$ no). 
Non-serious violent offence. Whether the index offence was from a range of offences deemed serious, but without a component of violence. This included acts intended to cause injury, sexual assault and dangerous or negligent acts endangering persons $(1=$ yes, $0=$ no $)$. Break and enter offence. Whether the index offence was unlawful entry with intent/burglary, break and enter $(1=$ yes, $0=$ no $)$.

Theft offence. Whether the index offence was theft $(1=$ yes, $0=$ no $)$.

Property damage offence. Whether the index offence was property damage $(1=$ yes, $0=$ no).

Court appearance previously. Whether the young offender had previously attended youth courts prior to referral to a conference $(1=$ yes, $0=$ no $)$.

Number of prior events. The number of formal youth justice system contacts (i.e., formal police caution or youth court appearance) prior to referral to a conference (continuous measure).

\section{Cohort Characteristics.}

Of the 806 cohort members who had been referred by police to a conference, the majority were male (72.7\%) and non-Indigenous (70.6\%; Table 2). A small proportion of young people in the cohort came from areas characterised by low socioeconomic status $(14.9 \%)$, or remoteness $(5.6 \%)$. Young people tended to be referred to a conference for a property offence (such as theft $(33.3 \%)$, break and enter $(19.5 \%)$ and property damage $(17.6 \%))$ than an offence against the person (such as serious violent offence $(12.3 \%)$ or nonserious violent offence $(6.9 \%))$. The average age that a young person was first referred by police to a conference was $15.11(S D=1.32)$ years. The majority of young people in the cohort $(70.8 \%)$ had previously had some formal system contact with the youth justice system before referral to conference. While the maximum number of formal system contacts that a 
young person had before referral was 18 , young people in the cohort averaged $1.40(S D=$ 1.87) contacts before their first conference.

\section{[ Insert Table 2 about here]}

\section{Matching technique}

Matching has been identified as a means to address the problem of selection bias in observational studies, by approximating experimental conditions (Shadish, Clark, \& Steiner, 2008). The basic premise is to identify individuals from a group of non-participants (control group) who are similar to participants (treatment group) in all relevant pre-treatment characteristics. The logic of this approach is that if outcome differences exist between suitably matched treatment and control groups, then we may attribute these effects to the treatment (Stuart, 2010). To control for selection bias and create statistically equivalent groups of Indigenous and non-Indigenous young offenders to examine the impact of conferencing, we employed PSM (Rosenbaum \& Rubin, 1983).

The matching process was conducted with SPSS (version 22) using the PSM dialog (Thoemmes, 2012). We calculated propensity scores using a logistic regression with Indigenous status as the group indicator with 11 covariates, including socio-demographic, residential and offence characteristics, as well as the prior history of the young offender. We used nearest neighbour matching without replacement, and applied a caliper of 0.2 of the standard deviation of the logit of the propensity.

Of the 237 Indigenous cohort members 197 (83\%) were matched, signifying a large area of common support between the two groups. The large number of people who remain unmatched was due in part to the type of matching algorithm used, and specifically the use of a bandwidth or caliper in matching between groups. 


\section{Balancing Groups with PSM}

Before matching, we conducted a series of bivariate analyses to test for differences between the Indigenous and non-Indigenous cohort members on key covariates. In addition to calculating effect sizes of phi $(\varphi)$ and Cohen's $d$ (depending on measurement level), we also used estimations of standardised bias (SB) to assess the distance in distributions for covariates between Indigenous and non-Indigenous groups. According to Rosenbaum and Rubin (1985), a standardised absolute bias equal to or greater than $20 \%$ is an indication of imbalance. The results indicated that there were significant differences between the groups on seven of the 11 covariates included in the matching procedure.

At the time of the conference, Indigenous cohort members were younger $(M=14.92$ years, $S D=1.31)$ than non-Indigenous offenders $(M=15.18$ years, $S D=1.32)$. In terms of residential characteristics, Indigenous young people were more likely to live in areas classified as remote $(15.6 \%)$, or characterised by high disadvantage $(26.6 \%)$, than nonIndigenous young people $(1.4 \%$ and $10.0 \%$, respectively $)$ In terms of offending characteristics, Indigenous young people were more likely to attend a conference resulting from a break and enter offence $(24.1 \%)$ than non-Indigenous young people $(17.6 \%)$. In contrast, non-Indigenous young people were more likely to attend a conference resulting from a property damage offence than Indigenous offenders (19.5\% and $13.1 \%$, respectively). Finally, in terms of prior contact with the system, a greater proportion of Indigenous young people had attended court previously before referral to a conference $(24.5 \%)$ than nonIndigenous young people (12.3\%).

We repeated the bivariate analyses conducted pre-matching, to examine whether the matching process had resulted in a reduction of bias in covariates. The results showed no significant differences on any covariate between the matched groups (Table 3). 
Additionally, we plotted SB estimations of the covariates pre- and post-matching (Figure 1). This demonstrates the success of the PSM in achieving statistical balance between the groups, as there were five covariates with a SB greater than $20 \%$ before matching, and none after matching.

\section{[ Insert Figure 1 about here]}

\section{Results}

Reoffending within two years

We performed a chi-square test of independence to examine the association between Indigenous status and having formal system recontact within two years of the conference. The results indicated that Indigenous youth were significantly more likely than nonIndigenous youth to have recontact within two years of their first conference $\left(\chi^{2}(1, n=394)\right.$ $=4.52, p=.033, \varphi=.11)$. Of the matched Indigenous young offenders, $140(71 \%)$ had formal system recontact within two years of the conference, compared with $120(61 \%)$ of the nonIndigenous young offenders. In terms of an odds ratio, Indigenous young people had a rate of recontact within two years 1.58 times that of non-Indigenous young people.

\section{Reoffending and increasing severity}

Given that a large number of young offenders, both Indigenous and non-Indigenous had system recontact after attending their first conference, it was prudent to examine an additional dimension of recidivism. Thus, we conducted a chi-square test of independence to examine, for those young people who did have formal recontact, whether there was an association between Indigenous status and an increase in offence seriousness. While young non-Indigenous recidivists were more likely to have recontact for a more serious offence 
$(39 \%)$ than their Indigenous counterparts $(30 \%)$, this finding was non-significant $\left(\chi^{2}(1, n=\right.$ $307)=2.96, p=.086, \varphi=-.10)$.

Time-to-reoffence

We performed a Cox Proportional-Hazards regression survival analysis to examine whether there were differences in hazard or survival rates by race. The results indicated that there was a significant difference between the matched groups $\left(G^{2}(1, n=394)=8.80, p=\right.$ $.003, R^{2}=.02$ ). The hazard ratio indicated that the recidivism hazard for Indigenous young people was $1.41(95 \%$ C.I. 1.12 - 1.76) times higher than non-Indigenous young people (Figure 2). Non-Indigenous young people took significantly longer in days $(M=811.68, S D$ $=852.46)$ than their Indigenous counterparts $(M=556.51, S D=613.82)$ to either have formal system recontact, or 'age' out of the study after attending a conference.

[ Insert Figure 2 about here]

\section{Sensitivity analyses}

PSM relies on a range of covariates to achieve statistical balance between matched groups to address the issue of selection bias. There is, however, the potential for residual bias (hidden bias) from unobserved variables that simultaneously affect assignment into treatment and the outcome variable (Loughran, Wilson, Nagin, \& Piquero, 2015). We conducted Rosenbaum bounds (Rosenbaum, 2002) to provide quantitative statements of how large an impact unmeasured variables would need to invalidate our findings. We interpret gamma $(\Gamma)$ as an odds ratio, and can calculate the critical $\Gamma$ value at which we would alter our conclusion about our results due to unmeasured confounders. A hidden bias of a small magnitude (closer to $\Gamma=1$ ), indicates results more sensitive to hidden bias, while a larger magnitude implies that we can be confident in the reliability of our finding. 
As the outcome variable in our first analysis examining system recontact within two years was binary, we used the Mantel and Haenszel (1959) test statistic, as suggested by Aakvik (2001). Because we have used PSM to create quasi-experimental groups based on race, rather than on a 'treatment', the interpretation of the sensitivity analysis is less intuitive. The critical value of $\Gamma=1.43$ assumes that if the odds of one person being in the Indigenous group are $43 \%$ higher, or decreases the odds recidivism within two years in the group of Indigenous offenders by $43 \%$ because of different values on an unobserved covariate despite being identical on the matched covariates, our inference changes.

We also conducted a sensitivity analysis for the comparison of censored survival data suggested by Rosenbaum (2002) for the third analysis focused on the time-to-reoffence. The critical value of $\Gamma=1.35$ similarly assumes that if there is an unobserved confounder that increases the odds of being in the Indigenous group by $35 \%$, or decreases the hazard rate for Indigenous young people by $35 \%$ despite being identical on the matched covariates, our findings would be invalidated. However, with the lack of clear thresholds in relation to critical values, we can say that our results are moderately robust to hidden bias.

\section{Discussion}

The aim of this study was to examine whether there is a differential impact of conferencing on recidivism by race. The use of matching techniques allowed us to evaluate how effective conferencing was for reducing recidivism for Indigenous young people, compared to non-Indigenous young people. This is important, given that advocates champion conferencing as a means to address the key issue of over-representation of Indigenous young people in the criminal justice system.

Our results showed that after controlling for demographic, residential, offending and prior offending characteristics, Indigenous young people were significantly more likely to 
reoffend within two years of their first conference than non-Indigenous young people. When examining those who did have recontact, there was no difference between the groups in terms of the seriousness of the reoffending. However, the results of the survival analysis demonstrated that Indigenous young people had a significantly larger hazard ratio than their non-Indigenous counterparts, indicating that Indigenous young people had recontact with the system quicker.

Although these findings may be disappointing to advocates of RJ and those who hoped that conferencing would be a panacea for the over-representation of Indigenous young people, they should not be surprising. RJ approaches do not specifically focus on addressing risk factors associated with youth offending (such as substance misuse, low socioeconomic status, poor impulse control, involvement with delinquent peers, neighbourhood disorganisation, etc.). Rather, these processes aim to meet victim needs, elicit offender accountability, and restore the offender back into society through the key mechanism of reintegrative shaming. For some Indigenous young people who live in communities characterised by high levels of economic and social disadvantage (Weatherburn, 2014), there are concerns to what these young people are being restored to.

The implications for these findings highlight the need to address the risk factors underlying Indigenous people's contact with the criminal justice system. To address these risk factors, it might be necessary to integrate therapeutic, family, educational and employment components into the conference process, or the ability to refer offenders to existing programs in the community (Joudo, 2008; Little et al., 2011). However, the problem is that such programs are often inaccessible to young people in remote locations. Second, due to a lack of evidence-based programs, there remains uncertainty as to their effectiveness for Indigenous young people (Allard, 2011). Given the policy issues at stake, there is clearly 
scope for further research on programs that are effective at reducing recidivism by Indigenous young offenders.

Other benefits of RJ should dissipate any disappointment of these results related to reoffending. RJ approaches are associated with increased rates of victim and offender satisfaction (Gal \& Moyal, 2011; Van Camp \& Wemmers, 2013), seen as procedurally fair (Tyler et al., 2007), appears to elicit accountability in offenders (Kim \& Gerber, 2012), are more economically efficient and timely responses than traditional alternatives (Allard et al., 2014), and ultimately reduce or delay further contact with the criminal justice system, which in itself is criminogenic (Weatherburn, 2014). However, this research has not previously been examined based on race or ethnicity, and therefore is an area for future research.

In addition, research suggests that conferencing may still be more effective at reducing reoffending than attending a traditional youth court (Bergseth \& Bouffard, 2007, 2013; Little et al., 2011). Thus, conferencing remains an important tool in responding to youth offending, regardless of race.

Past criticisms of the youth justice system have centred on potential discrimination and bias, suggesting that the over-representation of Indigenous young people is due, in part, to the lower likelihood of diversion from formal court processing (Cunneen et al., 2005; Cunneen et al., 2016). However, our data disputes this. Rather, police referred Indigenous young people to conferences at a higher rate than their relative proportion within the cohort. Rather than Indigenous young people not being afforded the same opportunity for diversion, the results indicate that conferencing has a differential impact on recidivism by race. That is, conferencing appears to be less effective for reducing recidivism by Indigenous young people post-conference than for non-Indigenous young people. Given these findings, an increase in rates of diversion to conferencing is unlikely to result in reducing the over-representation of Indigenous young people within the youth justice system in Queensland. Rather, we argue 
that to address Indigenous over-representation, we need to look beyond the criminal justice system and address the underlying issues of disadvantage.

\section{Limitations}

The current study is not without limitations. First, to ensure the generalisability of this research, four domains of covariates would ideally be present, including: (i) what a person 'is' (e.g., gender, race, and age); (ii) what a person has 'done' (e.g., offence type and criminal history); (iii) what a person 'has' (e.g., mental illness or substance abuse); and (iv) what has 'been done' to the person (e.g., victimisation). Such covariates would be informed by the literature on risk factors of anti-social behaviour (for example, see Jolliffe, Farrington, Piquero, Loeber, \& Hill, 2017; Ray, Thornton, Frick, Steinberg, \& Cauffman, 2016). The propensity score model used in this study only included covariates from two of these categories; what the person 'is' and what the person has 'done'. It was not possible to include covariates in the model from other categories as these data were not available. For example, Indigenous offenders are more likely to suffer from mental health problems that increase the probability of reoffending (Halsey, 2010), or reside in areas characterised by high levels of disadvantage and are more likely to experience victimisation and trauma (Weatherburn, 2014). It may be from these domains of has' and 'been done' where strategies on how to address the issue of Indigenous over-representation may be found.

The second potential limitation is that we relied exclusively on the use of administrative data pertaining to officially recorded contacts that young people had with the youth justice system. Administrative data may underestimate the true extent of offending by participants, reflect biases in agency activity, or fail to control for discretionary decision within the criminal justice system (Piquero et al., 2014). Given that young people are more likely to come into contact with police due to the nature of their offending being public and in 
groups (Cunneen \& White, 2011), administrative data may not underestimate youth offending to the same extent it does for adult offending. Further, recent research has found strong congruence between the use of official and self-reported data (Piquero et al., 2014), suggesting that the impact of using official data on generalisability might be minimal.

Finally, as our stringent matching resulted in a substantial number of individuals remaining unmatched, we note that our analyses were conducted on a sub-sample and may not be representative of the broader sample and population. Further research is required to assess the generalisability of these results to other populations and settings.

\section{Conclusion}

The over-representation of Indigenous people in the Australian criminal justice system remains a critical social policy issue. The situation appears worse within the youth justice system, highlighted by high rates of young Indigenous people within youth detention. Advocates suggest that an increased use of conferencing will reduce Indigenous overrepresentation, recommending the increased use of diversion of young Indigenous offenders away from formal processing by courts to a conference. However, our findings indicate that this is unlikely to impact dramatically on the rate of Indigenous over-representation. Our results provide evidence for the differential effectiveness of conferencing on recidivism outcomes by race. Indigenous young offenders were significantly more likely to have system recontact within two years of their first conference, than matched non-Indigenous young people. The result of the survival analysis further indicates that Indigenous young people had a hazard rate significantly higher than matched non-Indigenous offenders. Thus, an increased use of conferencing - despite having better reoffending outcomes than traditional court practices - will not be successful in addressing the issue of Indigenous over-representation. There remain large disparities between Indigenous and non-Indigenous people (and their 
communities) in key indicators such as education, health and employment. To be successful in addressing this crucial social policy issue, the increase in diversion must accompany improvements in these other indicators that are risk factors for the involvement in crime and offending. 
i 'First Nations People' refers to groups of people who were indigenous to territories in pre-colonial societies, and consider themselves distinct from other sectors of the societies now prevailing in those territories, or parts of them (Sanders, 1999). In this paper, we refer specifically to Aboriginal and Torres Strait Islander people in Queensland, Australia. The terms 'First Nations people', 'Aboriginal and Torres Strait Islander people' and 'Indigenous people' are used interchangeably in this article.

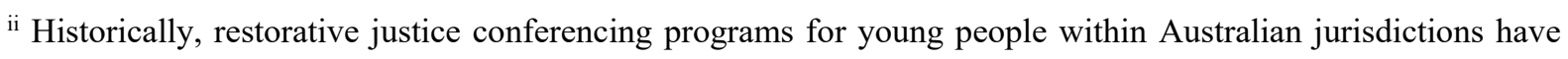
been called 'youth justice conferencing', 'juvenile conferencing' or 'community conferencing' interchangeably. In this paper, we use the term 'conferencing' to refer to such programs.

iii The focus of this study is the first conference that a young person attends. While some young people were conferenced on multiple occasions, we focus on the first conference to control for its impact.

iv Traditionally, the use of race as a concept enables comparisons between groups (such as White and Black) in crime and justice patterns, or the over-representation of racial and ethnic minority groups within the criminal justice system. The over-representation of Indigenous Australians within the criminal justice system in Australia mirror those of the Black, Hispanic and Native American populations in the United States of America (Hartney \& Vuong, 2009), and of the Indigenous population in Canada (Corrado, Kuehn, \& Margaritescu, 2014). In this paper, we operationalise 'race' as the dichotomy between an offender self-identifying as being an Indigenous or not. 


\section{References}

Aakvik, A. (2001). Bounding a Matching Estimator: The Case of a Norwegian Training Program. Oxford Bulletin of Economics and Statistics, 63(1), 115-143.

Allard, T. (2011) Indigenous young people and the justice system: Establishing an evidencebase. In A, Stewart, T. Allard \& S. Dennison (Eds) Evidence Based Policy \& Practice in Youth Justice. Sydney: The Federation Press, 28-45.

Allard, T., Stewart, A., Smith, C., Dennison, S., Chrzanowski, A., \& Thompson, C. (2014). The monetary cost of offender trajectories: Findings from Queensland (Australia). Australian \& New Zealand Journal of Criminology, 47(1), 81-101.

Australian Bureau of Statistics. (2006). Statistical Geography Volume 1 - Australian Standard Geographical Classification (ASGC). (Cat. No. 1216.0). Canberra: Australian Bureau of Statistics.

Australian Bureau of Statistics. (2008). Socio-Economic Indexes for Areas (SEIFA) Technical Paper. (Cat. No. 2039.0.55.001). Canberra: Australian Bureau of Statistics.

Australian Bureau of Statistics. (2009). National Offence Index. (Cat. 1234.0.55.001). Canberra: Australian Bureau of Statistics.

Australian Bureau of Statistics. (2013). Estimates of Aboriginal and Torres Strait Islander Australians, June 2011. (Cat. No. 3238.0.55.001). Canberra: Australian Bureau of Statistics.

Australian Institute of Health and Welfare. (2012). National best practice guidelines for data linkage activities relating to Aboriginal and Torres Strait Islander people. Canberra: AIHW.

Australian Institute of Health and Welfare. (2016). Youth Detention Population in Australia 2016. Canberra: AIHW. 
Baffour, T. D. (2006). Ethnic and Gender Differences in Offending Patterns: Examining Family Group Conferencing Interventions among At-Risk Adolescents. Child and Adolescent Social Work Journal, 23(5-6), 557-578.

Bergseth, K. J., \& Bouffard, J. A. (2007). The long-term impact of restorative justice programming for juvenile offenders. Journal of Criminal Justice, 35(4), 433-451.

Bergseth, K. J., \& Bouffard, J. A. (2013). Examining the Effectiveness of a Restorative Justice Program for Various Types of Juvenile Offenders. International Journal of Offender Therapy and Comparative Criminology, 57(9), 1054-1075.

Blagg, H. (1997). A Just Measure of Shame? Aboriginal Youth and Conferencing in Australia. The British Journal of Criminology, 37(4), 481-501.

Bouffard, J., Cooper, M., \& Bergseth, K. (2016). The Effectiveness of Various Restorative Justice Interventions on Recidivism Outcomes Among Juvenile Offenders. Youth Violence and Juvenile Justice, O(0), 1-16.

Braithwaite, J. (1989). Crime, shame and reintegration. Cambridge: Cambridge University Press.

Braithwaite, J. (2002). Restorative Justice and Responsive Regulation. Melbourne: Oxford University Press.

Calhoun, A., \& Pelech, W. (2010). Responding to young people responsible for harm: a comparative study of restorative and conventional approaches. Contemporary Justice Review, 13(3), 287-306.

Caverley, D., Cotter, A., \& Halla, E. (2010). Youth custody and community services in Canada, 2008/2009. Juristat: Canadian Centre for Justice Statistics, 30(1), 4-35.

Corrado, R. R., Kuehn, S., \& Margaritescu, I. (2014). Policy issues regarding the overrepresentation of incarcerated Aboriginal young offenders in a Canadian context. Youth Justice, 14, 40-62. 
Cunneen, C. (1997). Community Conferencing and the Fiction of Indigenous Control. Australian \& New Zealand Journal of Criminology, 30(3), 292-311.

Cunneen, C., Collings, N., \& Ralph, N. (2005). Evaluation of the Queensland Aboriginal and Torres Strait Islander Justice Agreement. Sydney: Crime and Justice Research Network, University of Sydney Law School Institute of Criminology.

Cunneen, C., Goldson, B., \& Russell, S. (2016). Juvenile Justice, Young People and Human Rights in Australia. Current Issues in Criminal Justice, 28(2), 173-190.

Cunneen, C., \& White, R. (2011). Juvenile justice: Youth and crime in Australia (4th ed.). South Melbourne: Oxford University Press.

Daly, K. (2002). Restorative justice: The Real Story. Punishment \& Society, 4(1), 55-79.

de Beus, K., \& Rodriguez, N. (2007). Restorative justice practice: An examination of program completion and recidivism. Journal of Criminal Justice, 35(3), 337-347.

Department of Corrections. (2007). Over-representation of Māori in the criminal justice system: An exploratory report. Wellington: Policy, Strategy and Research Group, Department of Corrections.

Farrington, D. P., \& Bennett, T. (1981). Police Cautioning of Juveniles in London. British Journal of Criminology, 21(2), 123-135.

Gal, T., \& Moyal, S. (2011). Juvenile Victims in Restorative Justice: Findings from the Reintegrative Shaming Experiments. British Journal of Criminology, 51(6), 10141034.

Halsey, M. (2010). Imprisonment and prisoner re-entry in Australia. Dialectical Anthropology, 34(4), 545-554.

Hartney, C., \& Vuong, L. (2009). Created equal: racial and ethnic disparities in the US criminal justice system. Oakland: National Council on Crime and Delinquency. 
Hayes, H., \& Daly, K. (2003). Youth Justice Conferencing and Reoffending. Justice Quarterly, 20(4), 725-764.

Hayes, H., \& Daly, K. (2004). Conferencing and Re-offending in Queensland. Australian and New Zealand Journal of Criminology, 37(2), 167-191.

Higgins, G. E., Jennings, W. G., Jordan, K. L., \& Gabbidon, S. L. (2011). Racial Profiling in Decisions to Search: Preliminary Analysis Using Propensity-Score Matching. International Journal of Police Science \& Management, 13(4), 336-347.

Higgins, G. E., Ricketts, M. L., Griffith, J. D., \& Jirard, S. A. (2013). Race and Juvenile Incarceration: A Propensity Score Matching Examination. American Journal of Criminal Justice, 38(1), 1-12.

Hunter, B. (2009). Indigenous social inclusion: Insights and challenges for the concept of social inclusion. Family Matters, 82, 52-61.

Johnston, E. (1991). Royal Commission into Aboriginal Deaths in Custody. Canberra: Australian Government Publishing Service.

Jolliffe, D., Farrington, D. P., Piquero, A. R., Loeber, R., \& Hill, K. G. (2017). Systematic review of early risk factors for life-course-persistent, adolescence-limited, and lateonset offenders in prospective longitudinal studies. Aggression and Violent Behavior, $33,15-23$.

Joudo, J. (2008). Responding to substance abuse and offending in Indigenous communities: review of diversion programs. Canberra: Australian Institute of Criminology.

Kim, H. J., \& Gerber, J. (2012). The Effectiveness of Reintegrative Shaming and Restorative Justice Conferences: Focusing on Juvenile Offenders' Perceptions in Australian Reintegrative Shaming Experiments. International Journal of Offender Therapy and Comparative Criminology, 56(7), 1063-1079. 
Latimer, J., Dowden, C., \& Muise, D. (2005). The Effectiveness of Restorative Justice Practices: A Meta-Analysis. The Prison Journal, 85(2), 127-144.

Lipsey, M. W. (2009). The Primary Factors that Characterize Effective Interventions with Juvenile Offenders: A Meta-Analytic Overview. Victims \& Offenders, 4(2), 124-147.

Little, S., Allard, T., Chrzanowski, A., \& Stewart, A. (2011). Diverting young Indigenous people from the Queensland youth justice system. Brisbane: Griffith University.

Loughran, T. A., Wilson, T., Nagin, D. S., \& Piquero, A. R. (2015). Evolutionary regression? Assessing the problem of hidden biases in criminal justice applications using propensity scores. Journal of Experimental Criminology, 11(4), 631-652.

Mantel, N., \& Haenszel, W. (1959). Statistical Aspects of the Analysis of Data From Retrospective Studies of Disease. JNCI: Journal of the National Cancer Institute, 22(4), 719-748.

Marchetti, E., \& Daly, K. (2007). Indigenous Sentencing Courts: Towards Theoretical and Jurisprudential Model. Sydney Law Review, 29(3), 415-444.

Morris, A. (2002). Critiquing the critics: A brief response to critics of restorative justice. British Journal of Criminology, 42(3), 596-615.

Nagin, D. S., \& Weisburd, D. (2013). Evidence and Public Policy. Criminology \& Public Policy, 12(4), 651-679.

Piquero, A. R., Schubert, C. A., \& Brame, R. (2014). Comparing Official and Self-report Records of Offending across Gender and Race/Ethnicity in a Longitudinal Study of Serious Youthful Offenders. Journal of Research in Crime and Delinquency, 51(4), $526-556$

Productivity Commission. (2016). Report on Government Services 2016. 
Quilty, S., Levy, M. H., Howard, K., Barratt, A., \& Butler, T. (2004). Children of prisoners: a growing public health problem. Australian and New Zealand Journal of Public Health, 28(4), 339-343.

Ray, J. V., Thornton, L. C., Frick, P. J., Steinberg, L., \& Cauffman, E. (2016). Impulse Control and Callous-Unemotional Traits Distinguish Patterns of Delinquency and Substance Use in Justice Involved Adolescents: Examining the Moderating Role of Neighborhood Context. Journal of Abnormal Child Psychology, 44(3), 599-611.

Ridgeway, G. (2006). Assessing the Effect of Race Bias in Post-traffic Stop Outcomes Using Propensity Scores. Journal of Quantitative Criminology, 22(1), 1-29.

Rodriguez, N. (2007). Restorative Justice at Work: Examining the Impact of Restorative Justice Resolutions on Juvenile Recidivism. Crime \& Delinquency, 53(3), 355-379.

Rosenbaum, D. P. (2002). Observational Studies (2nd ed.). New York: Springer.

Rosenbaum, P. R., \& Rubin, D. B. (1983). The Central Role of the Propensity Score in Observational Studies for Causal Effects. Biometrika, 70(1), 41-55.

Rosenbaum, P. R., \& Rubin, D. B. (1985). Constructing a Control Group Using Multivariate Matched Sampling Methods That Incorporate the Propensity Score. The American Statistician, 39(1), 33-38.

Sanders, D. E. (1999). Indigenous peoples: Issues of definition. International Journal of Cultural Property, 8(1), 4-13.

Shadish, W. R. (2013). Propensity score analysis: promise, reality and irrational exuberance. Journal of Experimental Criminology, 9(2), 129-144.

Shadish, W. R., Clark, M. H., \& Steiner, P. M. (2008). Can Nonrandomized Experiments Yield Accurate Answers? A Randomized Experiment Comparing Random and Nonrandom Assignments. Journal of the American Statistical Association, 103(484), 1334-1344. 
Sherman, L. W., Strang, H., Mayo-Wilson, E., Woods, D. J., \& Ariel, B. (2015). Are Restorative Justice Conferences Effective in Reducing Repeat Offending? Findings from a Campbell Systematic Review. Journal of Quantitative Criminology, 31(1), 124.

Sherman, L. W., Strang, H., \& Woods, D. (2000). Recidivism Patterns in the Canberra Reintegrative Shaming Experiment. Canberra: Centre for Restorative Justice, Research School of Social Sciences, Australian National University.

Spruance, S. L., Reid, J. E., Grace, M., \& Samore, M. (2004). Hazard Ratio in Clinical Trials. Antimicrobial Agents and Chemotherapy, 48(8), 2787-2792.

Strang, H. (2001). Restorative justice programs in Australia : a report to the Criminology Research Council. Canberra: Australian Institute of Criminology.

Stringer, R. J., \& Holland, M. M. (2016). It's not all black and white: A propensity score matched, multilevel examination of racial drug sentencing disparities. Journal of Ethnicity in Criminal Justice, 14(4), 327-347.

Stuart, E. A. (2010). Matching methods for causal inference: A review and a look forward. Statistical Science, 25(1), 1-21.

Thoemmes, F. (2012). Propensity score matching in SPSS. arXiv preprint arXiv:1201.6385.

Tyler, T. (1990). Why People Obey the Law. New Haven, CT: Yale University Press.

Tyler, T. R., Sherman, L., Strang, H., Barnes, G. C., \& Woods, D. (2007). Reintegrative Shaming, Procedural Justice, and Recidivism: The Engagement of Offenders' Psychological Mechanisms in the Canberra RISE Drinking-and-Driving Experiment. Law \& Society Review, 41(3), 553-586.

Van Camp, T., \& Wemmers, J.-A. (2013). Victim satisfaction with restorative justice: More than simply procedural justice. International Review of Victimology, 19(2), 117-143. 
Weatherburn, D. (2014). Arresting Incarceration: Pathways out of Indigenous Imprisonment. Canberra, ACT: Aboriginal Studies Press.

Weatherburn, D., \& Lind, B. (2000). Delinquent-Prone Communities. Cambridge: Cambridge University Press.

Weatherburn, D., \& Macadam, M. (2013). A review of restorative justice responses to offending. Evidence Base, 1, 1-20.

Weatherburn, D., Snowball, L., \& Hunter, B. (2008). Predictors of Indigenous Arrest: An Exploratory Study. Australian and New Zealand Journal of Criminology, 41(2), 307322.

Wilson, H. A., \& Hoge, R. D. (2013). Diverting Our Attention to What Works: Evaluating the Effectiveness of a Youth Diversion Program. Youth Violence and Juvenile Justice.

Wong, J. S., Bouchard, J., Gravel, J., Bouchard, M., \& Morselli, C. (2016). Can At-Risk Youth Be Diverted From Crime?: A Meta-Analysis of Restorative Diversion Programs. Criminal Justice and Behavior, 43(10), 1310-1329.

Ye, Y., Bond, J., Schmidt, L. A., Mulia, N., \& Tam, T. W. (2012). Towards a Better Understanding of When to Apply Propensity Scoring: A Comparison with Conventional Regression in Ethnic Disparities Research. Annals of epidemiology, 22(10), 691-697. 
Table 1

Cohort's contact with the youth justice system and referrals to RJ conference, by gender and Indigenous status $(n=806)$

\begin{tabular}{|c|c|c|c|c|c|}
\hline \multirow[t]{2}{*}{ Gender } & \multirow[t]{2}{*}{ Indigenous status } & \multicolumn{2}{|c|}{$\begin{array}{l}\text { Contact with the youth } \\
\text { justice system }(n=7,900)\end{array}$} & \multicolumn{2}{|c|}{$\begin{array}{l}\text { Ever referred by police } \\
\text { to conference }(n=806)\end{array}$} \\
\hline & & $n$ & $\%$ & $n$ & $\%$ \\
\hline \multirow{2}{*}{ Male } & Indigenous & 963 & 18.6 & 170 & 29.0 \\
\hline & Non-Indigenous & 4,214 & 81.4 & 416 & 71.0 \\
\hline \multirow{2}{*}{ Female } & Indigenous & 470 & 17.3 & 67 & 30.5 \\
\hline & Non-Indigenous & 2,253 & 82.7 & 153 & 69.5 \\
\hline
\end{tabular}


Table 2

Descriptive statistics for Indigenous and non-Indigenous young offenders group and group comparisons before matching procedure $(n=806)$

\begin{tabular}{|c|c|c|}
\hline Variable & $n$ & $\%$ \\
\hline \multicolumn{3}{|l|}{ Demographic characteristics } \\
\hline \multicolumn{3}{|l|}{ Indigenous status } \\
\hline Indigenous & 237 & 29.4 \\
\hline Non-Indigenous & 569 & 70.6 \\
\hline \multicolumn{3}{|l|}{ Sex } \\
\hline Male & 586 & 72.7 \\
\hline \multirow[t]{2}{*}{ Female } & 220 & 27.3 \\
\hline & M & $S D$ \\
\hline \multirow[t]{2}{*}{ Age at conference } & 15.11 & 1.32 \\
\hline & $n$ & $\%$ \\
\hline \multicolumn{3}{|l|}{ Residential characteristics } \\
\hline \multicolumn{3}{|l|}{ Lowest Socioeconomic Area } \\
\hline Yes & 120 & 14.9 \\
\hline No & 686 & 85.1 \\
\hline \multicolumn{3}{|l|}{ Remote Location } \\
\hline Yes & 45 & 5.6 \\
\hline No & 761 & 94.4 \\
\hline \multicolumn{3}{|l|}{ Offence characteristics } \\
\hline \multicolumn{3}{|l|}{ Offence type } \\
\hline Serious Violent Offence & 99 & 12.3 \\
\hline Non-serious Violent Offence & 56 & 6.9 \\
\hline Break \& Enter & 157 & 19.5 \\
\hline Theft & 268 & 33.3 \\
\hline Property Damage & 142 & 17.6 \\
\hline Public order & 42 & 5.2 \\
\hline Justice procedures & 1 & 0.1 \\
\hline Drug & 12 & 1.5 \\
\hline Other & 29 & 3.6 \\
\hline \multicolumn{3}{|l|}{ Prior offending characteristics } \\
\hline \multicolumn{3}{|l|}{ Previous Youth Court Appearance } \\
\hline Yes & 128 & 15.9 \\
\hline \multirow[t]{2}{*}{ No } & 678 & 84.1 \\
\hline & $M$ & $S D$ \\
\hline Number of prior system contacts & 1.40 & 1.87 \\
\hline
\end{tabular}


Table 3

Descriptive statistics, bivariate comparisons and standardised differences between Indigenous and non-Indigenous young offender groups, before and after matching procedure

\begin{tabular}{|c|c|c|c|c|c|c|c|c|c|c|c|c|c|c|}
\hline & \multicolumn{7}{|c|}{ Before PSM $(n=806)$} & \multicolumn{7}{|c|}{ After PSM $(n=394)$} \\
\hline & \multicolumn{2}{|c|}{$\begin{array}{l}\text { Non-Indigenous } \\
\quad(n=569)\end{array}$} & \multicolumn{2}{|c|}{$\begin{array}{l}\text { Indigenous } \\
(n=237)\end{array}$} & \multicolumn{2}{|c|}{ Comparison } & \multirow[t]{2}{*}{ SB (\%) } & \multicolumn{2}{|c|}{$\begin{array}{l}\text { Non-Indigenous } \\
\quad(n=197)\end{array}$} & \multicolumn{2}{|c|}{$\begin{array}{l}\text { Indigenous } \\
(n=197)\end{array}$} & \multicolumn{2}{|c|}{ Comparison } & \multirow[t]{2}{*}{ SB $(\%)$} \\
\hline & $n$ & $\%$ & $n$ & $\%$ & $\chi^{2}$ & $\varphi$ & & $n$ & $\%$ & $n$ & $\%$ & $\chi^{2}$ & $\varphi$ & \\
\hline \multicolumn{15}{|l|}{ Demographic characteristics } \\
\hline Male & 416 & 73.1 & 170 & 71.7 & 0.16 & -0.01 & 3.1 & 142 & 72.1 & 142 & 72.1 & 0.00 & 0.00 & 0.0 \\
\hline \multicolumn{15}{|l|}{ Residential characteristics } \\
\hline Lowest socioeconomic area & 57 & 10.0 & 63 & 26.6 & $36.23^{* * *}$ & 0.21 & -43.8 & 34 & 17.3 & 39 & 19.8 & 0.42 & 0.03 & -6.7 \\
\hline Remote location & 8 & 1.4 & 37 & 15.6 & $64.05^{* * *}$ & 0.28 & -55.8 & 8 & 4.1 & 9 & 4.6 & 0.06 & 0.01 & -3.7 \\
\hline \multicolumn{15}{|l|}{ Offence Characteristics } \\
\hline Serious violent & 67 & 11.8 & 32 & 13.5 & 0.46 & 0.02 & -5.2 & 29 & 14.7 & 29 & 14.7 & 0.00 & 0.00 & 0.0 \\
\hline Non-serious violent & 42 & 7.5 & 14 & 5.9 & 0.56 & -0.03 & 5.9 & 12 & 6.1 & 13 & 6.6 & 0.04 & 0.01 & -2.1 \\
\hline Break \& enter & 100 & 17.6 & 57 & 24.1 & $4.47^{*}$ & 0.07 & -16.0 & 39 & 19.8 & 41 & 20.8 & 0.06 & 0.01 & -2.5 \\
\hline Theft & 192 & 33.7 & 76 & 32.1 & 0.21 & -0.02 & 3.6 & 68 & 34.5 & 68 & 34.5 & 0.00 & 0.00 & 0.0 \\
\hline Property damage & 111 & 19.5 & 31 & 13.1 & $4.76^{*}$ & -0.08 & 14.5 & 24 & 12.2 & 26 & 13.2 & 0.09 & 0.02 & -2.8 \\
\hline \multicolumn{15}{|l|}{ Prior offending characteristics } \\
\hline \multirow[t]{2}{*}{ Prior youth court appearance } & 70 & 12.3 & 58 & 24.5 & $18.55^{* * *}$ & 0.15 & -31.8 & 40 & 20.3 & 37 & 18.8 & 0.15 & -0.02 & 4.0 \\
\hline & $M$ & $S D$ & $M$ & $S D$ & $t$ & $d$ & SB (\%) & $M$ & $S D$ & $M$ & $S D$ & $t$ & $d$ & SB $(\%)$ \\
\hline \multicolumn{15}{|l|}{ Demographic characteristics } \\
\hline Age at conference & 15.18 & 1.32 & 14.92 & 1.31 & $2.60^{* *}$ & 0.20 & 20.1 & 14.83 & 1.29 & 14.88 & 1.35 & -0.37 & -0.04 & -3.7 \\
\hline \multicolumn{15}{|l|}{ Prior offending characteristics } \\
\hline Number of prior system contacts & 1.11 & 1.36 & 2.11 & 2.61 & $-5.63^{* * *}$ & -0.51 & -48.3 & 1.54 & 1.89 & 1.61 & 1.71 & -0.39 & -0.04 & -3.4 \\
\hline
\end{tabular}

Note: ${ }^{*} p<.05^{* *} p<.01^{* * *} p<.001 . \mathrm{PSM}=$ Propensity Score Matching. SB = Standardised Bias 


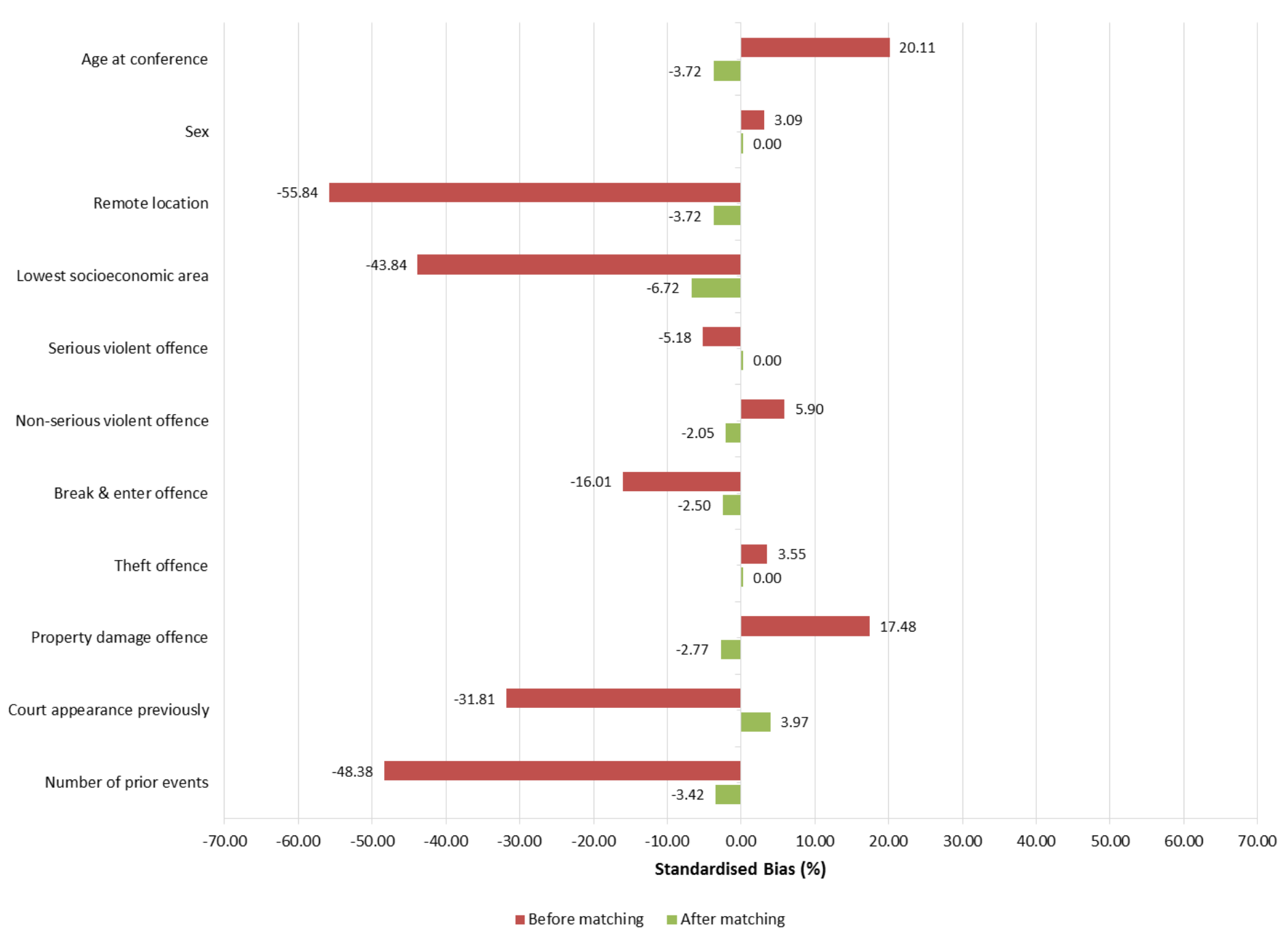

Figure 1. Balance on covariates using standardised bias (SB), before and after PSM procedure. 


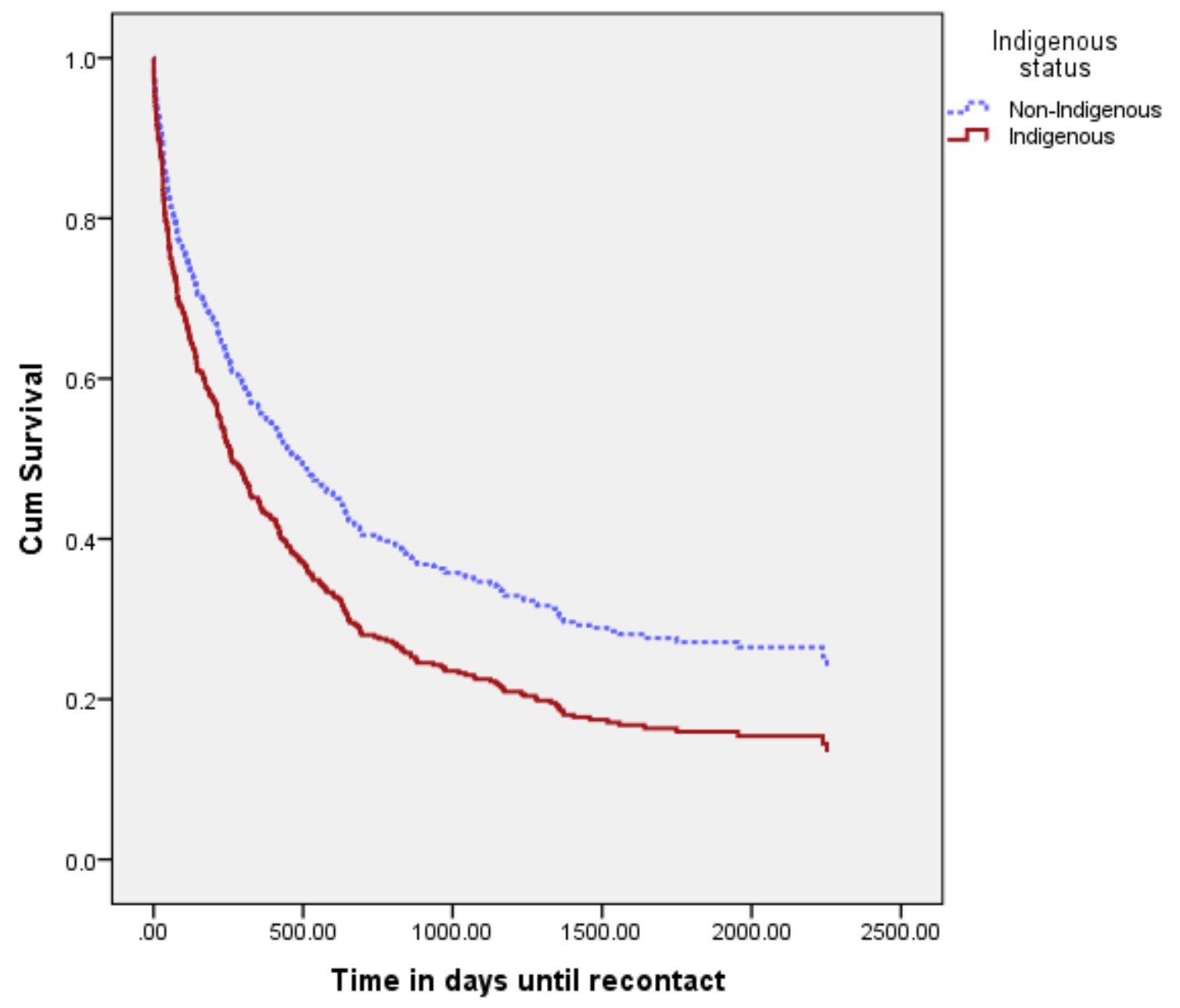

Figure 2. Cox Proportional-Hazards regression survival distribution of time (in days) to recontact or census date by race 